\title{
Measuring the costs and benefits of heart disease monitoring
} A Perry, S Capewell, A Walker, J Chalmers, A Redpath, K Major, C E Morrison, N Craig,
S Cobbe, W C S Smith

\begin{abstract}
Objective-To evaluate the costs and benefits of alternative systems of coronary heart disease monitoring in Scotland.

Design-An option appraisal was conducted to evaluate the costs and benefits of implementing a coronary heart disease monitoring system. This involved a review of existing Scottish datasets and relevant reports, specification of options, definition and weighting of benefit criteria by key stakeholders, assessment of options by experts, and costing of options. The options were assessed by 33 stakeholders (grouped as cardiologists, patient representatives, general practitioners, public health physicians, and policy makers), plus 13 topic experts.
\end{abstract}

Setting-Scotland (population 5.1 million).

Results-Between group mean benefit weights were: mortality rates and case fatality (10.6), quality of life (9.8), patient function (8.8), hospital activity (7.8), primary care activity (9.25), prescribing (5.72), socioeconomic impact (4.0), risk factors (7.4), prevalence (5.0), incidence (6.0), case registration (6.82), international comparability (4.2), breadth of coverage (8.8), and frequency (5.8). Differences between group weights were significant for prevalence $(\mathrm{p}=0.048)$ and international comparability $(\mathrm{p}=0.032)$. Four monitoring options were identified: a community epidemiology model, based on MONICA (monitoring trends and determinants in cardiovascular disease) study methodology applied to a series of eight representative communities, had the highest benefits, at an average annual discounted cost of approximately $£ 360000$; models based on the Australian cardiovascular disease monitoring scheme and on enhanced routine data offered fewer benefits at discounted average annual costs ranging from $£ 165000$ to $£ 195$ 000; finally, a coronary heart disease registry modelled on the Scottish Cancer Registry scheme would have had fewer benefits and substantially higher costs than the other options.

Conclusions-The most beneficial coronary heart disease monitoring system is the community epidemiology model, based on MONICA methodology. Option appraisal potentially offers an explicit and transparent methodology for evidence based policy development.

(Heart 2000;83:651-656)

Department of Put Liverpool, Liverpool

L69 3GB, UK

Greater Glasgow

Health Board, 350 St

Vincent St, Glasgow 3, UK

A Walker

C E Morrison

Information and Statistics Division, Trinity Park House, Edinburgh 5, UK

J Chalmers

A Redpath

Department of Medical Cardiology, Glasgow Royal Infirmary, Glasgow 31, UK

S M Cobbe

Department of Public Health, Ayrshire \& Arran Health Board, Ayr, UK

K Major

Department of Public Health, University of Aberdeen,

Aberdeen 25, UK

W C S Smith

Correspondence to:

Dr Capewell

email: capewell@

liverpool.ac.uk

Accepted 31 January 2000

Keywords: monitoring; surveillance; heart disease; option appraisal
Coronary heart disease remains a top national policy priority. Regular, valid monitoring (surveillance) is a key component of any such policy. The ideal coronary heart disease monitoring system should be able to assess the burden of coronary heart disease in the community; provide proper epidemiological information on the incidence and prevalence of acute myocardial infarction, angina, and heart failure; describe age and sex specific trends in different geographical areas; measure the need for services in both primary and secondary care; measure cardiovascular risk factor levels and trends; and assess the impact of medical, surgical, and preventive interventions. ${ }^{1-4}$

Current coronary heart disease monitoring in the National Health Service (NHS) has many deficiencies. Data on community based activity are limited, despite more than $80 \%$ of general practices having computerised patient records. ${ }^{5}$ Existing monitoring systems concentrate on acute episodes and deaths rather than on the disease burden in the population. Community management of angina and heart failure remains largely undocumented, and risk factor trends are similarly neglected.

Tunstall-Pedoe has outlined many of the problems which might be encountered in a coronary heart disease monitoring system. ${ }^{1}$
These include lack of pathological validation for cause of death, failure to record mild or "silent" infarctions, inadequate recording of acute and chronic medical care outside hospital, and lack of standardisation in cardiovascular risk factor measurement.

Finland, ${ }^{6}$ the USA, ${ }^{7-11}$ and Australia ${ }^{4}$ have already implemented comprehensive monitoring schemes. These offer coverage of risk factor prevalence, much enhanced data collection, and detailed analysis of acute coronary episodes.

Schemes for cancer registration and HIV surveillance have already proved the value of good quality monitoring information for decision makers. ${ }^{12}$ Better information will, however, be expensive. The additional costs and benefits of improved information therefore need to be critically examined. One possible technique for doing so is option appraisal, which is routinely used for capital projects and has shown its value in other non-capital areas such as priority setting. ${ }^{13}$ Option appraisal may also be suitable for the evaluation of new policies and new information systems, especially as it allows the benefits of the proposed service to be explicitly defined. ${ }^{14}$ The aim of the project described here was to use option appraisal to assess the costs and benefits of alternative 
options for monitoring coronary heart disease in Scotland.

\section{Methods}

OPTION APPRAISAL

The option appraisal followed the stages recommended by Henderson ${ }^{15}$ and HM Treasury. ${ }^{16}$ The stages include setting objectives, identification of options (including the existing system of monitoring coronary heart disease in Scotland), specification of benefit criteria, weighting the criteria to reflect their importance, scoring options against criteria, and then comparison of weighted scores with costs.

GENERATING OPTIONS

Options were identified from a 1996 policy review and from published reports. ${ }^{1-6}$ The project steering group then generated a long list of options, plus suboptions which could be added to any major option (such as population surveys, self contained modules, or research projects). The status quo was also included in order to facilitate comparisons. Reduced levels of monitoring were not considered.

A short list of options was assembled from the most promising major option and suboptions (table 1). In the sensitivity analysis, each option was compared with the next best option, with and without different suboptions.
IDENTIFYING AND MEASURING BENEFITS

Benefit criteria were defined in terms of the information that a monitoring system should contain according to experts and published reports. Fourteen benefit criteria emerged, selected on the basis of key characteristics of coronary heart disease monitoring systems (all fell within four categories: epidemiology, service utilisation, measuring effectiveness and outcomes, and system quality (table 2)).

\section{WEIGHTING AND VALUING THE BENEFITS}

Coronary heart disease monitoring information is of interest to many different stakeholders, each conceivably having quite different preferences regarding the content and quality of the system's output. The project working group identified five separate groups that would be involved in collecting or using this information:

- Planners and policy makers, represented by five members of the Scottish Office coronary heart disease priority team.

- Ten directors of public health in Scotland.

- Four cardiologists from the council of the Scottish Cardiac Society.

- Ten general practitioners from the Scottish General Medical Services Committee.

- Four patient representatives from the Scottish Association of Health Councils.

Each group was approached and given a brief presentation on the project and the methods of option appraisal. To elicit weights for the benefit

Table 1 Short list of options for monitoring coronary heart disease in Scotland

Option A: Status quo

Option B: Enhanced routine data model

Option B1: Enhanced routine data model plus risk factor surveys

Option C: Community epidemiology model

Option D: Australian cardiovascular disease monitoring scheme

Option D1: Australian model plus quality of life surveys

Option E: CHD registry

Option E1: CHD registry plus risk factor surveys

Option E2: CHD registry plus patient function and quality of life surveys

Option E3: CHD registry plus risk factor, patient function, and quality of life surveys
No dedicated central coordination or structure

National data collection of hospital activity and deaths

Cardiac surgery and angioplasty databases

Record linkage between inpatient episodes and death records possible

Quality assurance from the Information and Statistics Division in Edinburgh

Primary care data collection from a sample of self selected general practices

Dispensed prescription data analysable by general practitioner but not by diagnosis Ad hoc risk factor surveys

Central coordination from the Information and Statistics Division in Edinburgh Designated director of CHD monitoring, small support staff, including data manager and statistician

Enhanced capability for data linkage and harmonisation between routine datasets Patient function and quality of life surveys for discharged hospital patients

Accident and emergency database

Addition of national risk factor surveys as per option D

Central coordination. Nurses based in eight selected communities

Full myocardial infarction registration and extended CHD detection (including heart failure) from 80 spotter general practices in selected communities

Hospital and primary care use: attendances, investigations, admissions, bed use, interventions

Diagnostic definitions and quality assurance derived from WHO MONICA standards

Risk factor, patient function, and quality of life surveys for CHD patients in selected locations

Central office with researchers collating data from spotter practices and surveys Sentinel registers in hospitals for AMI based upon a simplified WHO MONICA protocol

National risk factor and health behaviour surveys

CHD population prevalence surveys

Addition of quality of life surveys as per option B

Central office at the Information and Statistics Division in Edinburgh

Routine links with hospital and general practice information systems for case notification

Regional data collection via peripatetic staff. Standard diagnostic definitions

Follow up investigations of reported sudden deaths

Addition of risk factor surveys as per option D

Addition of patient function and quality of life surveys as per option B

Addition of risk factor surveys (as option D) plus patient function and quality of life (as option B) 
Table 2 Benefit criteria used in weighting and scoring

\begin{tabular}{|c|c|c|}
\hline Category & Benefit criterion & Description \\
\hline \multirow[t]{4}{*}{ Service utilisation } & Hospital activity & $\begin{array}{l}\text { Includes information related to admissions and readmissions, plus surgical, medical and } \\
\text { preventive interventions in hospital. Does NOT include hospital prescribing (see Prescribing) }\end{array}$ \\
\hline & Primary care activity & $\begin{array}{l}\text { Includes information on consultations, interventions such as smoking advice and health } \\
\text { promotion. Also includes community activity and Scottish Ambulance Service information. } \\
\text { Does NOT include general practitioner prescribing (see Prescribing) }\end{array}$ \\
\hline & Prescribing & $\begin{array}{l}\text { Information on prescribing of CHD related treatments. This includes general practitioner } \\
\text { prescribing, hospital dispensing, pharmacy dispensing and information on over-the-counter } \\
\text { dispensing }\end{array}$ \\
\hline & Socioeconomic impact & $\begin{array}{l}\text { Information such as costs incurred by patients for access to services, days lost to illness, impact on } \\
\text { carers }\end{array}$ \\
\hline \multirow[t]{4}{*}{ Epidemiology } & Risk factors & $\begin{array}{l}\text { Information on CHD risk factors in the general population. These include hypertension, } \\
\text { hyperlipidaemia, smoking, diet, diabetes, family history, lifestyle, health related behaviour, } \\
\text { personality type }\end{array}$ \\
\hline & Prevalence & Prevalence in the population of myocardial infarction, angina, and heart failure \\
\hline & Incidence & Information on new cases of myocardial infarction, angina and heart failure in each year \\
\hline & Case registration & $\begin{array}{l}\text { Ability to register individual patients with myocardial infarction, angina and heart failure so that } \\
\text { they can be followed up }\end{array}$ \\
\hline \multirow[t]{3}{*}{$\begin{array}{l}\text { Measuring effectiveness } \\
\text { and outcomes }\end{array}$} & Mortality rates and case fatality & $\begin{array}{l}\text { Includes information on all deaths from CHD in the community and in hospital. Total CHD plus } \\
\text { diagnostic subgroups. Mortality rates in defined groups }\end{array}$ \\
\hline & Patient function & $\begin{array}{l}\text { Information on the physical functioning of patients diagnosed with CHD. Might include mobility, } \\
\text { activities of daily living, or angina grade }\end{array}$ \\
\hline & Quality of life & $\begin{array}{l}\text { Information on CHD patients' subjective perception of their wellbeing. Might include instruments } \\
\text { for generating quality adjusted life years }\end{array}$ \\
\hline \multirow[t]{3}{*}{ System quality } & $\begin{array}{l}\text { Compatibility for international } \\
\text { comparisons }\end{array}$ & $\begin{array}{l}\text { Ability to adhere to recognised specifications of surveys, diagnoses, or data interpretation that can } \\
\text { allow for direct comparisons with CHD statistics similarly compiled elsewhere }\end{array}$ \\
\hline & Breadth of coverage & $\begin{array}{l}\text { Ability to gather information that takes account of geographical and demographic differences } \\
\text { between communities }\end{array}$ \\
\hline & Frequency & $\begin{array}{l}\text { Capability to conduct trend analyses from regular data collection. How often surveys and analyses } \\
\text { are performed or disseminated }\end{array}$ \\
\hline
\end{tabular}

CHD, coronary heart disease.

criteria, the five groups were asked to distribute 100 points among the 14 criteria, based on the importance they attached to the various characteristics of a monitoring system. The distribution of these points thus reflected the relative importance of each criterion. Four groups chose to submit individual sets of benefit weights for each individual respondent, so a mean weight was then generated. The remaining group preferred to generate a single set of weights.

Respondents were asked to weight criteria ignoring the level of information currently provided under the status quo. This approach allowed groups such as patient representatives to express their preferences without requiring detailed knowledge of existing NHS information systems.

SCORING THE OPTIONS

Each option was then scored in terms of how well it would achieve the 14 benefits. Fourteen
United Kingdom experts in different coronary heart disease related areas were invited to take part in the scoring, and 13 agreed to.

Scorers were given detailed option specifications and asked individually to assess each option by scoring each benefit criterion (from 0 , the poorest possible level of monitoring, up to 100 , representing perfection). Each was then interviewed to allow them to explain their judgements. Scorers were explicitly asked not to consider cost.

IDENTIFYING, MEASURING, AND VALUING COSTS The perspective taken was the cost of each option to the NHS. Costs (including a plausible range for best and worse case scenarios) were identified by approaching organisations or individuals with appropriate expertise. Costs were examined both undiscounted, and discounted at $6 \%$ per annum (the HM Treasury suggested discount rate).

Table 3 Benefit weighting by the five stakeholder groups

\begin{tabular}{|c|c|c|c|c|c|c|}
\hline \multirow[b]{2}{*}{ Benefit criteria } & \multicolumn{5}{|c|}{ Benefit weighting group mean values (range) } & \multirow[b]{2}{*}{$\begin{array}{l}\text { Between group } \\
\text { mean }\end{array}$} \\
\hline & $\begin{array}{l}\text { Directors of public } \\
\text { health }(n=10)\end{array}$ & $\begin{array}{l}\text { Scottish General Medical } \\
\text { Services Committee } \\
(n=10)\end{array}$ & $\begin{array}{l}\text { Scottish Cardiac } \\
\text { Society }(n=4)\end{array}$ & $\begin{array}{l}\text { Scottish Association of } \\
\text { Health Councils }(n=4)\end{array}$ & $\begin{array}{l}\text { Scottish Office } C H D \\
\text { priority team }(n=1)\end{array}$ & \\
\hline Hospital activity & $7.2(0$ to 10$)$ & 7.70 (3 to 12$)$ & $10.50(3$ to 19$)$ & 8.75 (5 to 20$)$ & 5 & 7.83 \\
\hline Primary care activity & $7.00(0$ to 10$)$ & $10.50(3$ to 20$)$ & 9.50 (4 to 19$)$ & 11.25 (5 to 20$)$ & 8 & 9.25 \\
\hline Prescribing & $4.00(0$ to 6$)$ & $8.10(4$ to 12$)$ & 5.75 (2 to 10$)$ & 5.75 (3 to10) & 5 & 5.72 \\
\hline Socioeconomic impact & $4.10(0$ to 7$)$ & $4.70(1$ to 8$)$ & 3.75 ( 1 to 5$)$ & $5.50(0$ to 15$)$ & 2 & 4.01 \\
\hline Risk factors & $7.70(0$ to 10$)$ & 9.10 (5 to 14$)$ & 6.25 (4 to10) & $3.75(0$ to 10$)$ & 10 & 7.36 \\
\hline Prevalence & $9.40(5$ to 25$)$ & $6.90(2$ to 11$)$ & 5.75 (2 to10) & $3.00(0$ to 5$)$ & 0 & 5.01 \\
\hline Incidence & 9.30 (5 to 25$)$ & 6.40 (3 to 11$)$ & $5.00(2$ to 8$)$ & 9.50 (5 to 20$)$ & 0 & 6.04 \\
\hline Case registration & $4.10(0$ to 6$)$ & $5.50(3$ to 10$)$ & $5.00(2$ to 10$)$ & $9.50(5$ to 20$)$ & 10 & 6.82 \\
\hline $\begin{array}{l}\text { Mortality rates and } \\
\text { case fatality }\end{array}$ & 11.70 (5 to 20$)$ & $11.40(6$ to 25$)$ & $13.25(8$ to 20$)$ & $6.50(0$ to 10$)$ & 10 & 10.57 \\
\hline Patient function & 10.55 (5 to 20$)$ & 8.00 (4 to 12$)$ & $12.25(5$ to 30$)$ & $8.00(0$ to 20$)$ & 5 & 8.76 \\
\hline Quality of life & 10.65 (5 to 20$)$ & $6.30(2$ to 10$)$ & 11.50 (5 to 30$)$ & 15.50 (5 to 30$)$ & 5 & 9.79 \\
\hline $\begin{array}{l}\text { Compatibility for } \\
\text { international } \\
\text { comparisons }\end{array}$ & $5.60(0$ to 10$)$ & 4.80 (2 to 10$)$ & 4.25 (3 to 5 ) & 1.25 (0 to 3$)$ & 5 & 4.18 \\
\hline Breadth of coverage & $4.35(0$ to 10$)$ & $6.60(4$ to 12$)$ & 4.25 (0 to 10$)$ & 9.00 (3 to 15$)$ & 20 & 8.84 \\
\hline Frequency & $4.35(0$ to 10$)$ & $4.00(2$ to 5$)$ & $3.00(1$ to 5$)$ & 2.75 ( 1 to 5$)$ & 15 & 5.82 \\
\hline
\end{tabular}


Table 4 Scoring of five options by 13 topic experts

\begin{tabular}{|c|c|c|c|c|c|}
\hline \multirow[b]{2}{*}{ Benefit criteria } & \multicolumn{5}{|c|}{ Option score median values (range) } \\
\hline & Status quo & $\begin{array}{l}\text { Enhanced } \\
\text { routine data }\end{array}$ & $\begin{array}{l}\text { Community } \\
\text { epidemiology } \\
\text { model }\end{array}$ & $\begin{array}{l}\text { Australian } \\
\text { cardiovascular } \\
\text { disease model }\end{array}$ & CHD registry \\
\hline Hospital activity & $50(30$ to 80$)$ & $70(50$ to 90$)$ & 75 (40 to 90$)$ & $65(45$ to 85$)$ & $80(35$ to 90$)$ \\
\hline Primary care activity & $20(5$ to 40$)$ & $40(7$ to 60$)$ & $60(30$ to 80$)$ & $50(20$ to 85$)$ & $40(20$ to 80$)$ \\
\hline Prescribing & $30(20$ to 90$)$ & 50 (30 to 91$)$ & 70 (40 to 92$)$ & 55 (30 to 92$)$ & 60 (35 to 95$)$ \\
\hline Socioeconomic impact & $10(2$ to 20$)$ & $10(2$ to 50$)$ & $10(2$ to 70$)$ & $10(2$ to 70$)$ & $10(2$ to 60$)$ \\
\hline Risk factors & $50(20$ to 80$)$ & $50(25$ to 80$)$ & 70 (35 to 90$)$ & $60(30$ to 85$)$ & $60(25$ to 80$)$ \\
\hline Prevalence & $40(10$ to 70$)$ & $55(30$ to 80$)$ & $70(50$ to 90$)$ & $58(30$ to 85$)$ & $60(20$ to 95$)$ \\
\hline Incidence & $40(5$ to 70$)$ & $52(25$ to 75$)$ & $70(40$ to 90$)$ & $52(15$ to 85$)$ & $51(20$ to 95$)$ \\
\hline Case registration & $30(5$ to 60$)$ & $40(25$ to 65$)$ & $60(25$ to 95$)$ & $50(25$ to 80$)$ & $50(20$ to 90$)$ \\
\hline Mortality rates and case fatality & $55(20$ to 80$)$ & $65(30$ to 80$)$ & $80(50$ to 90$)$ & $65(40$ to 90$)$ & $65(42$ to 95$)$ \\
\hline Patient function & $5(0$ to 10$)$ & $50(20$ to 80$)$ & $70(30$ to 85$)$ & $50(20$ to 80$)$ & $5(0$ to 10$)$ \\
\hline Quality of life & $5(0$ to 10$)$ & $50(20$ to 80$)$ & $70(30$ to 90$)$ & $10(0$ to 50$)$ & $10(0$ to 40$)$ \\
\hline $\begin{array}{l}\text { Compatibility for international } \\
\text { comparisons }\end{array}$ & $50(25$ to 90$)$ & $50(25$ to 90$)$ & $70(50$ to 95$)$ & 65 (40 to 95$)$ & 55 (35 to 90$)$ \\
\hline Breadth of coverage & $60(35$ to 85$)$ & $60(40$ to 85$)$ & $70(55$ to 95$)$ & $70(50$ to 95$)$ & $65(50$ to 90$)$ \\
\hline Frequency & $60(25$ to 75$)$ & $60(25$ to 85$)$ & $70(63$ to 90$)$ & $70(50$ to 80$)$ & 65 (35 to 90$)$ \\
\hline
\end{tabular}

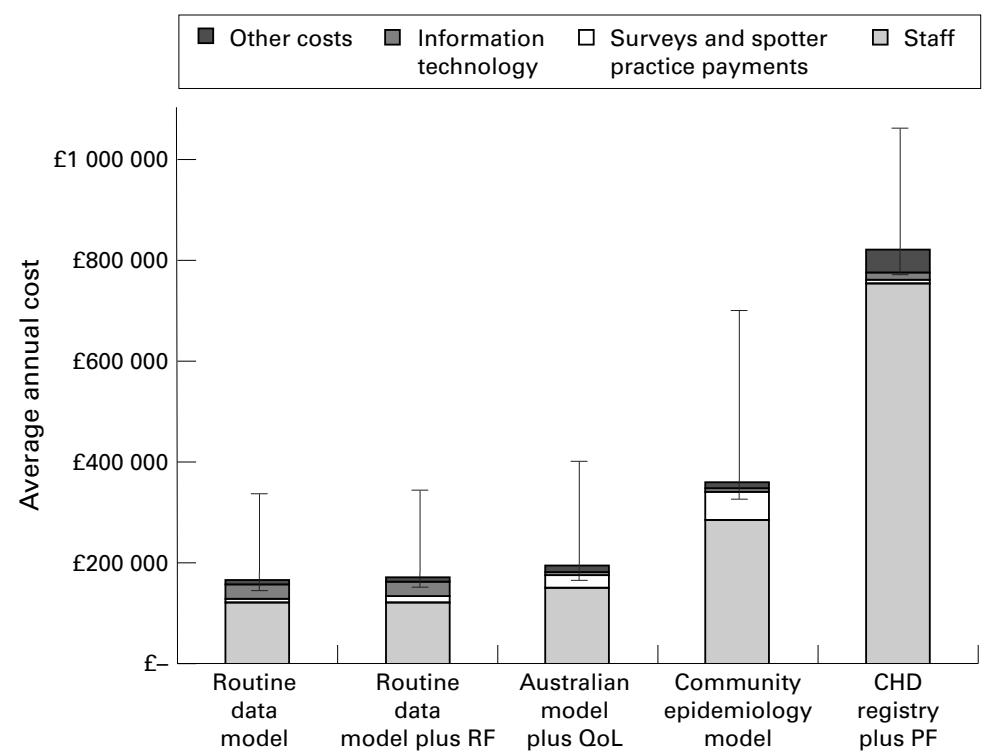

Figure 1 Four highest scoring monitoring options: estimated average annual costs (based on 10 year forecast and 6\% annual discount rate). CHD, coronary heart disease; QoL, quality of life; $P F$, patient function surveys; $R F$, risk factor surveys.

To account for periodic surveys, average annual costs were calculated over a time horizon of 10 years. A longer span was considered unrealistic, given the expected innovations in NHS information technology. All costs were held at 1998 levels.

OPTION SELECTION USING WEIGHTED BENEFIT SCORES

For each option, the option score was multiplied by the benefit weight to produce a total weighted benefit score. Those options which cost more than an alternative yet yielded fewer benefits were then discarded. Options were evaluated in terms of total cost and incremental costs over the next best option. Unquantified benefits and cost variability were also considered.

\section{STATISTICAL ANALYSES AND SENSITIVITY} ANALYSES

Group scores were summarised using means and medians as appropriate. The sensitivity analysis revolved around four key elements: benefit weights, option scores, costs, and option features. Several options were remodelled in the sensitivity analysis to include additional features. By noting the judgements behind scorers' decisions for options including similar features, it was possible to estimate the effect that their addition might have on the option score. ${ }^{17}$ Differences between those groups who submitted mean weights were tested for each benefit criterion using the Kruskal-Wallis test.

\section{Results}

BENEFIT WEIGHTS

Five groups produced benefit weights (table 3). Between group mean benefit weights were: hospital activity (7.8), primary care activity (9.25), prescribing (5.72), socioeconomic impact (4.0), risk factors (7.4), prevalence (5.0), incidence (6.0), case registration (6.82), mortality rates and case fatality (10.6), patient function (8.8), quality of life (9.8), international comparability (4.2), breadth of coverage (8.8), frequency (5.8). The highest weights were generally awarded to criteria capturing outcome measures. The Scottish Cardiac Society and the directors of public health awarded around one third of their weights to these criteria alone. Weighters valued good primary care data as highly as hospital activity data. Weights for prevalence and incidence showed quite large variations both within and between groups. Socioeconomic impact and international compatibility received low weights from all groups.

The highest weights for primary care activity came from the general practitioners and the patient representatives, at 10.5 and 11.3, respectively. The Scottish Office policy makers reserved their highest weight (20) for breadth of coverage. Differences between group mean weights were significant between directors of public health and general practitioners for prevalence $(\mathrm{p}=0.048)$, and between directors of public health, general practitioners, and patient representatives for international comparability $(\mathrm{p}=0.032)$.

The ranges of mean and individual benefit values were tested in the sensitivity analysis. 
Table 5 Costs and total weighted scores for different options

\begin{tabular}{llll}
\hline Option & $\begin{array}{l}\text { Total weighted } \\
\text { benefit score }\end{array}$ & $\begin{array}{l}\text { Undiscounted } \\
\text { cost }\end{array}$ & $\begin{array}{l}\text { Discounted } \\
\text { cost (6\%) }\end{array}$ \\
\hline Community epidemiology model & 6744 & $£ 457952$ & $£ 359289$ \\
Australian model plus quality of life & 5582 & $£ 248588$ & $£ 194905$ \\
CHD registry plus patient function and quality of life & 5568 & $£ 1052753$ & $£ 821613$ \\
Enhanced routine data plus risk factor surveys & 5251 & $£ 211783$ & $£ 171431$ \\
Australian model & 5190 & $£ 248588$ & $£ 194905$ \\
Enhanced routine data & 5178 & $£ 204782$ & $£ 165315$ \\
CHD registry & 4782 & $£ 1042753$ & $£ 813811$ \\
Status quo & 3566 & - & - \\
\hline
\end{tabular}

MONITORING OPTIONS

Ten options and suboptions were shortlisted, based on four models: an enhanced routine data model which built on the existing arrangement; a community epidemiology model, based on World Health Organisation MONICA (monitoring trends and determinants in cardiovascular disease) methodology and involving eight representative communities; a model based on the Australian cardiovascular monitoring scheme; and a coronary heart disease registration model based on the Scottish Cancer Registry scheme (table 1).

OPTION SCORES

Thirteen topic experts scored the five options against the 14 benefit criteria. The highest median scores went to the community epidemiology model for 13 of the 14 criteria (table 4 ).

OPTION COSTS

Discounted average annual option costs ranged from $£ 165315$ for the enhanced routine data model to $£ 827728$ for a coronary heart disease registry model (fig 1 ).

Staff accounted for the large majority of costs in every option. Over and above the costs quantified in the analysis, the enhanced routine data and coronary heart disease registry options would make considerable use of the centralised information resources already available at the Scottish Information and Statistics Division. All options were likely to increase the amount of doctor and nurse time spent cataloguing details. The community epidemiology and Australian cardiovascular disease monitoring scheme models were likely to be the most costly in terms of patient time for filling in survey forms. The community epidemiology model would also require patients to attend physical examinations and would therefore incur costs for travel and time off work.

WEIGHTED SCORES AND CREATION OF HYBRID OPTIONS

All 646 combinations of weights and scores possible for the four basic and enhanced options were analysed (34 sets of weights and 19 sets of scores, including means and

Table 6 Incremental costs per benefit point for four highest scoring options

\begin{tabular}{lllll}
\hline Option & $\begin{array}{l}\text { Discounted } \\
\text { total costs }\end{array}$ & $\begin{array}{l}\text { Incremental } \\
\text { cost }\end{array}$ & $\begin{array}{l}\text { Incremental } \\
\text { benefit }\end{array}$ & $\begin{array}{l}\text { Incremental cost } \\
\text { per benefit point }\end{array}$ \\
\hline $\begin{array}{c}\text { Community epidemiology } \\
\text { model }\end{array}$ & $£ 359289$ & $£ 164384$ & 1162 & $£ 141.47$ \\
$\begin{array}{c}\text { Australian model plus } \\
\text { quality of life }\end{array}$ & $£ 194905$ & $£ 23474$ & 330 & $£ 71.13$ \\
$\begin{array}{c}\text { Enhanced routine data plus } \\
\text { risk factors }\end{array}$ & $£ 171431$ & $£ 6116$ & 74 & $£ 82.65$ \\
$\begin{array}{l}\text { Enhanced routine data } \\
£ 165315\end{array}$ & $£ 165315$ & 1612 & $£ 102.55$ \\
\hline
\end{tabular}

medians). The community epidemiology option had the highest total benefit score in 603 of the 646 combinations.

Further analysis was based on mean benefit weights and median scores from scorers. The coronary heart disease registry and the original Australian cardiovascular disease option were then discarded, both having higher costs than other options yet yielding fewer benefits for all scenarios (table 5).

Ranking of the remaining options according to total benefits remained the same in each scenario: community epidemiology model, followed by an Australian model upgraded with a quality of life patient survey, then enhanced routine data upgraded with risk factor surveys, and finally the original enhanced routine data model. In each case, more benefits led to higher costs (tables 5 and 6 ).

\section{Discussion}

IMPLICATIONS FOR DECISION MAKERS

This project has shown first, that superior strategies for monitoring coronary heart disease are available, feasible, and not particularly expensive, particularly when set in the context of the total cost of cardiac disease. ${ }^{1-4}$ It thus has considerable value for the NHS. Second, it has shown that improved primary care and outcomes monitoring are of paramount concern. Third, key stakeholders have a range of different needs from a monitoring scheme. ${ }^{5}$

Our project identified, developed, and examined four major options for monitoring coronary heart disease in Scotland, in addition to the status quo. Once the Scottish Cancer Registry model had been discarded, the three remaining options each contributed progressively higher benefits as their costs increased. Highest benefit scores were seen for the community epidemiology model, at an estimated average annual cost of around $£ 360000$ after discounting. The higher scores and costs principally reflected the benefits from rigorous community monitoring but also the quality assured methodology and standardisation, based on MONICA methodology. ${ }^{2}$

\section{STUDY LIMITATIONS}

All option appraisals have limitations. Benefit criteria have to be selected early on. In this project, some criteria turned out to be less than ideal when the scoring stage was reached. Although this presented an issue when interpreting scores, additional criteria might have overly complicated the benefit weighting process. ${ }^{15}$

Ideally, scoring would have taken place in one session attended by all scorers or through a 
consensus generation process. Unfortunately this proved impracticable. However, such a process might have disguised genuine differences in opinion between experts. ${ }^{15} 16 \mathrm{Had}$ resources permitted, we would have consulted larger numbers of stakeholders and topic experts. However, we suspect that the results would not have been very different.

True costs were difficult to gather as they are often subsumed within the overall costs of the agencies or systems in which the coronary heart disease monitoring data are gathered. Also, patient costs were not included. However, as elsewhere, staff salaries dominated. ${ }^{4} 61014$

The results of benefit weighting and scoring need to be interpreted with care. Benefit weights are assumed to be cardinal because one point given to "incidence" represented one less point available for other criteria. However, option scores may only reflect an ordinal scale with an approximate indication of the strength of preference. Although total weighted benefit scores are listed in table 5, they are therefore best interpreted as indicating an overall ranking of options. ${ }^{15}$

\section{RECOMMENDATIONS}

The project identified several further issues for research. These include a programme budget for resources currently spent on coronary heart disease monitoring as part of routine data collection, and an assessment of the benefits of high quality monitoring for related disease groups, such as peripheral vascular disease and stroke, which could be added for little extra cost. $^{34}$

Option appraisal was found to offer a transparent methodology for assessing the costs and benefits of a range of competing options for monitoring coronary heart disease. ${ }^{15} 16$ The results of this appraisal should be of relevance to the many groups with an interest in NHS disease monitoring-policy makers, planners, health care professionals, patients, and the public. Option appraisal should be considered more often when such policy challenges arise.
We thank the groups who provided weights: the Scottish Office coronary heart disease priority team, the directors of public health in Scotland, the council of the Scottish Cardiac Society, the Scottish General Medical Services Committee, and the Scottish Association of Health Councils. We are very grateful to the individual coronary heart disease experts who scored the detailed options: Dr J Clarke (Information and Statistics Division, Edinburgh), Dr P Doyle (Department of Health, London), Dr J Dunbar (general practitioner, Dundee), Dr P Hanlon (Department of Public Health, University of Glasgow), Dr N Hicks (Anglia and Oxfordshire Health Authority), Dr M McWhirer (For halley Health Mc Wreater lege, London). We thank the Chief Scientist's Office of the Scottish Office for funding this project.

1 Tunstall-Pedoe $\mathrm{H}$. Monitoring coronary heart disease in the community: why and how? In: Marmot M, Elliott P, eds. Coronary heart disease epidemiology: from aetiology to public health. Oxford: Oxford Medical Publications, 1992 .

2 Fulton M. Monitoring coronary heart disease in Scotland. Edinburgh: Health Monitoring Group, Scottish Office Home and Health Department, 1991.

3 Fulton M. Home and Health Department policy review of coronary heart disease: questions posed. Edinburgh: Scottish Office Home and Health Department, 1993.

4 Bennett S, Dobson A, Magnus P. Outline of a national monitoring system for cardiovascular disease. Canberra: Australian toring system for cardiovascular disease. Can

5 Public Health Policy Unit Policy Review Group. Coronary heart disease in Scotland: report of a policy review. Edinburgh: HMSO, 1996

6 Puska P, Tuomilehto J, Nissinen A, et al, eds. The North Karelia project: 20 year results and experiences. Helsinki: The National Public Health Institute, 1995.

7 Feinleib M, Breslow NE, Detels R. Cohort studies. In: Detels R, Holland WW, McEwen J, et al, eds. Oxford textbook of public health. Oxford: Oxford University Press, 1997.

8 Dawber TR, Kannel WB, Lyell LP. An approach to longitudinal studies in a community: the Framingham study. Ann NY Acad Sci 1963;107:539-56.

9 Farquhar JW, Fortmann SP, Maccoby N, et al. The Stanford five-city project: design and methods. Am $\mathcal{f}$ Epidemiol 1985;122:323-34.

10 Murray DM. Design and analysis of community trials: lessons from the Minnesota heart health program. Am $\mathcal{F}$ Epidemiol 1995;142:569-74.

11 Carleton RA, Lasater TM, Assaf A, et al. The Pawtucket heart health program: I. An experiment in population-based
disease prevention. Rhode Island Med $f$ 1987;70:533-8.

12 Donaldson L. Registering a need. BMF 1992;305:597-8.

13 Breen D. Setting priorities: a framework for the assessment of health care priorities in Scottish Health Boards. Health Bull 1991;49:34-9.

14 Lock C. What value do computers provide to NHS hospitals? BMF 1996;312:1407-10

15 Henderson J. Appraising options. SOAP 2. HERU Series of option appraisal papers. Aberdeen: University of Aberdeen, 1984.

16 HM Treasury. Investment appraisal in the public sector. London: HMSO, 1982.

17 Briggs A, Sculpher M, Buxton M. Uncertainty in the economic evaluation of health care technologies: the role of sensitivity analysis. Health Econ 1994;3:95-104 